Note: This is a post-review and pre-print version of the article. It may not exactly replicate the authoritative document to be published in Journal of Research in Personality.

\title{
Two Experience Sampling Studies Examining the Variation of Self-Control Capacity and Its Relationship with Core Affect in Daily Life ${ }^{1}$
}

Chao Zhang, Karin C. H. J. Smolders, Daniël Lakens, Wijnand A. IJsselsteijn Eindhoven University of Technology

\section{Author note:}

Corresponding author is Chao Zhang, Technische Universiteit Eindhoven, Postbus 513, 5600 MB EINDHOVEN, Email: c.zhang.5@tue.nl. All data, materials, and analyses scripts for the current paper are available at Open Science Framework: https://osf.io/hguz4/. This research did not receive any specific grant from funding agencies in the public, commercial, or notfor-profit sectors.

\section{Acknowledgments}

The authors want to thank Sabrina Thai and Dr. Elizabeth Page-Gould for their generous help during the development and production of our experience sampling apps.

\footnotetext{
${ }^{1}$ All authors contributed to the study conceptualization, data collection, and report writing. Data analyses were mainly done by Chao Zhang and Karin Smolders. The experience sampling app used was developed mainly by Chao Zhang.
} 


\begin{abstract}
To facilitate a better understanding of the role of self-control capacity in self-control processes, we examined its variation at intraindividual and interindividual levels, and positioned it in a nomological network with core affect. In two experience sampling studies, 286 university students reported their self-control capacity and core affect for a week. Results revealed larger person-to-person than day-to-day variation in self-control capacity, while its moment-to-moment variation could be weakly modeled as a diurnal pattern. Interindividually, participants with higher self-control capacity were happier and less stressed, but intraindividually higher self-control capacity was mainly associated with higher alertness and energetic arousal. Our results imply that self-control capacity is better conceptualized as a composition of interrelated sub-constructs rather than as a unified resource.
\end{abstract}

Keywords: trait self-control; state self-control capacity; core affect; diurnal pattern; experience sampling; cosinor fitting; inter and intraindividual differences

Word count: 11060, 6739 (main text) 


\section{Introduction}

As one of the hallmarks of human behavior, self-control has always been an important research topic in psychology and other behavioral sciences (Duckworth, 2011). Despite the lasting debate about the nature of self-control (e.g., Inzlicht \& Berkman, 2015; Kurzban, 2012), self-control is generally described as inhibiting one's responses to immediate rewards (e.g., eating a delicious chocolate bar) for the sake of pursuing long-term goals, for example, to lose weight or to be healthier. (cf. Loewenstein, 2000). For decades, theorists have been puzzled by the ability of mankind to value abstract goals over concrete short-term rewards (Kanfer \& Karoly, 1972), while at the same time people often fail to utilize this ability (Baumeister \& Heatherton, 1996). There are many factors that may influence self-control outcomes, such as the nature and strength of temptation in a self-control task (e.g., Hur, Koo, \& Hofmann, 2015) and the personal value of a long-term goal (e.g., Saunders \& Inzlicht, 2018). Among all the factors, self-control capacity as a person factor has been very central for the explanation in both folk theories (Bergen, 2011) and scientific models of self-control (Baumeister, Vohs, \& Tice, 2007; Kotabe \& Hofmann, 2015; Robinson, Schmeichel, \& Inzlicht, 2010). Its central role is perhaps grounded in the casual observations as well as empirical evidence that the ability of controlling oneself differs greatly between individuals (de Ridder, Lensvelt-Mulders, Finkenauer, Stok, \& Baumeister, 2012) as well as within individuals (e.g., Randles, Harlow, \& Inzlicht, 2017). For personality psychology, examining the interindividual and intraindividual differences in self-control capacity is of primary importance to improve our understanding of how people exert self-control.

Mischel and colleagues provided the first demonstration of the compelling effects of self-control capacity in the 1980s (Mischel, Shoda, \& Peake, 1988; Mischel, Shoda, \& Rodriguez, 1989). In a series of experiments, young children showed large differences in their ability to delay gratification (e.g., to receive more candies if they could withhold 
themselves from eating one candy for several minutes), and this individual difference was associated with their achievements much later in life. Although research on the origins of these differences has just begun (e.g., Hofmann, Gschwendner, Friese, Wiers, \& Schmitt, 2008), the significance of interindividual differences in self-control capacity have been suggested in a variety of domains (for a review, see de Ridder et al., 2012). For example, lower trait self-control is associated with lower academic achievements (Duckworth \& Seligman, 2005) and poorer health (Crescioni et al., 2011; Moffitt et al., 2011).

Adding to the substantial correlational evidence, the experimental paradigm of egodepletion (Muraven, Tice, \& Baumeister, 1998) and its associated strength model (Baumeister et al., 2007) further established the special status of self-control capacity in selfcontrol research. According to numerous ego-depletion studies (for a review, see Hagger et al., 2010), when people exert their self-control in an initial task, their performance in a second unrelated task that demands self-control worsened. This effect led to the view that self-control capacity is a resource that is domain-general and limited. However, recent metaanalyses failed to demonstrate convincing evidence for an ego-depletion effect, after correcting the literature for publication bias (Carter, Kofler, Forster, \& McCullough, 2015; Etherton et al., 2018). More critically, a recent large multi-lab pre-registered replication study did not find support for a domain-general limited resource view of self-control (Hagger, et al., 2016).

Although the strength model seems too simplistic based on the empirical support, the concept of self-control capacity is still central to several more recent models of self-control (e.g., Hall \& Fong, 2007; Hofmann, Friese, \& Strack, 2009; Kotabe \& Hofmann, 2015; Robinson et al., 2010; but see Inzlicht \& Schmeichel, 2012; Inzlicht, Schmeichel, \& Macrae, 2013). Without direct evidence, it is perhaps prudent to be skeptical about the theoretical status of self-control capacity, especially because resource-like constructs have long been 
criticized as seemingly intuitive but lacking true exploratory power (see Navon, 1984). A specific question is whether and how self-control capacity is distinct from core affect in their causal roles of influencing self-control processes and outcomes. In the valence-arousal model (Russell \& Barrett, 1999), core affect is defined as the change of a neurophysiological state underlying daily prototypical emotions (e.g., happiness, fear, anger, etc.) and can be expressed as subjective experiences on the valence (feeling good or bad) and arousal (feeling sleepy or activated) dimensions. The close relationship between core affect and self-control processes is both intuitive and supported by empirical research, as for example acute stress or tense arousal undermines self-control (e.g., Maier, Makwana, \& Hare, 2015) and a certain level of arousal or alertness is required for the functioning of attention and cognitive control (e.g., Thomas et al., 2000). Moreover, some recent theories have positioned affect at the core of cognitive control (Pessoa, 2009) and higher-level self-regulatory processes (Inzlicht, Bartholow, \& Hirsh, 2015; Saunders \& Inzlicht, 2018; also see Carver \& Scheier, 1990). For example, in the appraisal framework by Saunders and Inzlicht (2018), conflict-elicited negative affect is proposed as a driving force for mobilizing self-control. Combining the empirical evidence and theoretical considerations, it is possible that the state variation of core affect is the major person-factor to explain self-control outcomes, which may at the same time give rise to the phenomenological feelings that capacity of self-control varies. One may even compare self-control capacity to emotional episodes (e.g., fear or anger), in the sense that they are psychologically constructed based on a momentary state of core affect and additional appraisal processes (Russell, 2003), rather than being causal entities. Given these open questions, it is valuable as a first step to accurately describe the interindividual and intraindividual variations of self-control capacity, and to examine how these variations are associated with the variation of core affect (i.e., to build a nomological network, Cronbach \& Meehl, 1955). We report here two experience sampling studies to fulfill these objectives with 
the hope to facilitate future theoretical work on the role of self-control capacity in self-control processes.

Firstly, we measure both trait self-control and self-reported state self-control capacity in a multi-session multi-day experience sampling protocol to differentiate the variation of selfcontrol capacity at person-to-person, day-to-day, and moment-to-moment levels. We also aim to examine whether moment-to-moment variation can be explained by a time-of-day effect, and especially as a diurnal pattern, using a statistical technique called cosinor fitting (e.g., Hasler, Mehl, Bootzin, \& Vazire, 2008; Murray et al., 2009). There are clear indications for diurnal patterns in people's core affect, such as arousal levels (e.g., Smolders, de Kort, \& van den Berg, 2013; Stone et al., 2006; Wood \& Magnello, 1992), and valence (Stone et al., 2006; Murray et al., 2009). A similar pattern in self-control capacity can be predicted based on its close link to the affective system, and this hypothesis was indirectly supported by a study in which students' performance in an online learning platform showed a diurnal pattern over the day (Randles et al., 2017). We use a self-report measure of state self-control capacity to examine its diurnal patterns more directly.

Secondly, we follow the valence-arousal model (Russell \& Barrett, 1999) to measure four dimensions of core affect - valence, pure arousal, energetic arousal, and tense arousal (i.e., feeling of stress) - in the same experience sampling protocol. Thus, the relationships between self-control capacity and core affect can be quantified not only as correlations between trait self-control and dimensions of core affect, but also as disaggregated betweenperson and within-person correlations based on repeated state measures (see Curran \& Bauer, 2011). Previous studies have demonstrated that trait self-control is associated with valence (Daly, Baumeister, \& MacLachlan, 2014; Galla \& Wood, 2015; Hofmann, Luhmann, Fisher, Vohs, \& Baumeister, 2014) and tense arousal (Bowlin \& Baer, 2012; Galla \& Wood, 2015; Hofmann et al., 2014), using survey, daily diary, and experience sampling methods. These 
results suggest that people with higher trait self-control are also slightly happier in their daily lives (meta-analytic $r=0.26$ ) and experience less psychological stress (meta-analytic $r=$ 0.28; for forest plots with our studies added, see Figure $2 \& 3$ in the discussion ${ }^{2}$ ). We replicate these results and extend these findings to include within-person correlations. Moreover, although arousal is clearly related to cognitive performance (Thomas et al., 2000) and its link to self-control capacity has been suggested (Randle et al., 2017), we provide a first direct description of the association.

As the two experience sampling studies are very similar in their design and statistical analyses, we report the method and results of the two studies together in the following sections.

\section{Method $^{3}$}

\subsection{Participants}

Study 1 was conducted within a larger experience sampling project in September 2015. In total, 172 Bachelor students at Eindhoven University of Technology participated in the data collection as partial fulfillment for a course. From this sample, 140 students provided permission to use their data for scientific research, so all analyses are based on this subset. The final sample consisted of 85 men and 55 women, and the median age was 19 (18-26, SD $=2.43)$. Study 2 was conducted in the same setting as Study 1 in September 2016. Out of the 163 students, 146 provided permission to use their data for scientific research. The final sample consisted of 83 men and 63 women, and the median age was $18(17-25, S D=1.75)$. Both studies were conducted in the third and fourth week of the academic year when students were not yet under the pressure of deadlines or exams.

\footnotetext{
${ }^{2}$ Meta-analyses and forest plots were done using the R package metafor (Viechtbauer, 2010)

${ }^{3}$ Raw data, scripts, and other materials of the two experience sampling studies are available at Open Science Framework: https://osf.io/hguz4/. As our analyses focused on describing correlational patterns rather than testing specific hypotheses, we did not pre-register our data analyses.
} 
The sample sizes were limited by the number of students enrolled in the course, which was deemed sufficient because analyses at measurement level (results in section 3.3, 3.5) were well-powered to detect even very small correlations with over 5000 observations. The intensively repeated measurements were also necessary to accurately measure diurnal patterns of the variables of interest. For the analyses at the person level (i.e., effects of trait self-control, section 3.4), sensitivity analyses in G*Power v3.192 revealed that our sample sizes in Study 1 and Study 2 were able to detect minimum effect sizes of $\rho=0.230$ and $\rho=$ 0.234 respectively, given an alpha level of 0.05 and $80 \%$ power. These effect sizes were just below the meta-analytic effect sizes of the correlations of trait self-control with affective valence and stress $(r=0.26$ and $r=-0.28)$.

\subsection{Apparatus}

A mobile experience sampling app was developed for the studies by the first author based on the open-source framework Experience Sampler ${ }^{4}$ (Thai \& Page-Gould, 2017). The framework is a Cordova-based application template, supporting fast development of customized experience sampling apps for both Android and iOS platforms. In both studies, participants downloaded the app on their own smartphones to answer the experience sampling questionnaires.

\subsection{Measurements}

In both studies, trait self-control was measured by the brief version of the Trait SelfControl Scale (Tangney, Baumeister, \& Boone, 2004). The scale is based on a comprehensive conceptualization of self-control and has been shown to have good internal reliability (alpha $=0.83$ and 0.85 in Tangney et al., 2004; alpha $=0.77$ and 0.83 in our studies), good test-retest reliability (0.87 in Tangney et al., 2004), and to correlate relatively well with behavioral

\footnotetext{
${ }^{4}$ A tutorial to get started with Experience Sampler by Sabrina Thai and Elizabeth Page-Gould can be found on http://www.experiencesampler.com/
} 
indicators of self-control outcomes (de Ridder et al., 2012). Participants indicated to what extent they agreed with 13 statements on 5-point scales ranging from 1-Completely disagree to 5-Completely agree, such as "I am good at resisting temptation" and "I wish I had more self-discipline".

We measured state self-control capacity using selected items from the State SelfControl Scale (Ciarocco, Twenge, Muraven, \& Tice, 2015). With the intention to capture different aspects of state self-control, but not to overburden our participants, four items were selected, namely general willpower (Right now, I feel my willpower is gone), concentration (Right now, it would take a lot of effort for me to concentrate on something), urge-control (Right now, I am having a hard time controlling my urges), and motivation (Right now, I am motivated to pursuit my (long-term) goals ${ }^{5}$ ). Participants responded to the items on 7-point scales, ranging from 1-Not true to 7-Very true. In a post-hoc content analysis on the State Self-Control Scale, our selection turned out to cover four out of the total six theoretical subconstructs identified. Conceptually, the two omitted sub-constructs - mental fatigue and tense arousal - were captured when measuring the energetic and tense arousal dimensions of core affect. We decided to analyze the four items separately in order to explore potential subconstructs in state self-control capacity and their variations, and to assess the reliability and validity of a potential short composite scale. According to a recent review on construct validity (Strauss \& Smith, 2009), focusing on cohesive unidimensional rather than complex constructs should help to describe nomological networks more precisely.

The measurements of core affect followed the valence-arousal model of core affect (Russell \& Barrett, 1999). In Study 1, each dimension of core affect was measured by a single item to minimize the burden on participants. Specifically, affective valence was

\footnotetext{
${ }^{5}$ This item was adapted as the original item was simply "I am motivated", and the phrase "long-term" was only added in Study 2. The reason was to emphasize long-term goals, and to match a related item in the Total Trait Self-Control Scale (Tangney et al., 2004).
} 
measured on one 7-point bipolar scale, ranging from 1-Very bad to 7-Very good. Energetic arousal was measured on one 7-point unipolar scale, ranging from 1-Not at all to 7-Very energetic. Tense arousal or stress was measured on one 7-point scale, ranging from 1-Not at all stressful to 7-Very stressful. Sleepiness was measured by the 9-point Karolinska Sleepiness Scale (Åkerstedt \& Gillberg, 1990) which included the following labels: 1Extremely sleepy, 3-Sleepy, but no difficulty remaining awake, 5-Neither alert nor sleepy, 7Alert, and 9-Extremely alert. In Study 2, two changes were made to the measurements. First, in order to increase reliability of the measures (cf. Schimmack, 2003), two items were used for each dimension of core affect, except that the standard 1-item Karolinska Sleepiness Scale was unchanged. Second, bipolar scales were used for all variables as recommended by Russell and Carroll (1999). As a result, two 7-point scales each were used for affective valence (Unpleasant-Pleasant, and Sad-Happy), and for energetic arousal (Inactive-Active, and Depleted-Energetic). For the dimension of tense arousal or stress, two 7-point bipolar items (Relaxed-Nervous, and Calm-Tense) were added to the unipolar item used in Study $1^{6}$.

\subsection{Procedure}

Both studies were introduced to the participants during one of their lectures in an introduction to psychology course. They were instructed to download the experience sampling app on their smartphone and to use it for one week. One day prior to the start of the study, participants indicated in the app when they normally wake up and go to sleep on weekdays and weekends. Between the self-reported wake-up time and sleep time, they were prompted eight times a day to answer the experience sampling questionnaires. The notifications were triggered by a semi-random algorithm to ensure that the adjacent two

\footnotetext{
${ }^{6}$ Initially, stress was considered as a different construct from tense arousal, but the correlation between the two measures turned out to be very high and their relationships with other constructs were almost identical. Thus, we report stress and tense arousal as the same construct. Our current position is that even though the conceptualization of stress may be broader (e.g., to include stressors and behavioral responses), feelings of stress overlaps with the tense arousal dimension of core affect.
} 
sessions were always at least one hour apart. In each experience sampling questionnaire, the state questions described above were presented in the following order on separate pages: affective valence, stress, energetic arousal, sleepiness, and state self-control (Study 1), or affective valence, energetic arousal, tense arousal, sleepiness, stress, and state self-control (Study 2). To prevent a drop of response rate, we sent two motivational messages to the participants during the study (on the $3^{\text {rd }}$ and $6^{\text {th }}$ day since the beginning of the study). Trait self-control was measured in a separate online questionnaire either before (Study 1) or after the sampling period (Study 2).

\subsection{Data analysis ${ }^{7}$}

Given the three-level crossed design of our studies (all participants completed surveys in all seven days of a week, and in all 8 sessions from waking-up to sleep), we first built variance component models (multilevel null models) to decompose variance in each variable to difference sources. For variables with single-item measures, three-level models were built, resulting in variance from person (P), day-of-week (D), session number (S), and their interactions (see Equation 1). For variables with multiple-item measures, four-level models were built, resulting in variance from person (P), day-of-week (D), session number (S), item (I), and their interactions (see Equation 2). After variance decompositions, we followed generalizability theory (Cronbach, Gleser, Nanda, \& Rajaratnam, 1972; Webb, Shavelson, \& Haertel, 2006) to compute between-person and within-person reliability coefficients for the measurements used in the studies. Specifically, generalizability coefficients $\left(E_{\rho}^{2}\right)$ as measures of between-person reliability were computed (see Equation 3, based on Webb et al., 2006), which indicated the reliability of obtaining relative ranks of participants in terms of the

\footnotetext{
${ }^{7}$ Initially, we also looked at the effects of weekday/weekend on core affect and self-control capacity, and whether diurnal patterns and correlation patterns differ between weekdays and weekends. However, as no main effects of weekday/weekend were found and differences in diurnal and correlation patterns were negligible, we do not report these results in the Results section.
} 
measured variables when observed scores were averaged over all measurement facets (e.g., days, sessions, and items). Coefficients for within-person reliability of change $\left(R_{c}\right)$ were computed to estimate the precision of measuring systematic changes in participants' selfcontrol capacity and core affect over the 56 observations (see Equation 4, based on Cranford et al., 2015; Shrout $\&$ Lane, 2011). $R_{c}$ could only be calculated for multiple-item measures, for which variance components of the person by day by session interaction $\left(\sigma_{p * d * s}\right)$ could be separated from measurement error. Alternatively, we also computed averages of the observation-specific Cronbach's alpha coefficients for multiple-item measures $\left(\alpha_{\text {ave }}\right.$ in Table 1 and 3).

$$
\begin{gathered}
Y_{i j k}=\beta_{0}+P_{i}+D_{j}+S_{k}+(P D)_{i j}+(P S)_{i k}+(D S)_{j k}+\varepsilon_{i j k} \\
Y_{i j k l}=\beta_{0}+P_{i}+D_{j}+S_{k}+I_{l}+(P D)_{i j}+(P S)_{i k}+(P I)_{i l}+(D S)_{j k}+(D I)_{j l} \\
+(S I)_{k l}+(P D S)_{i j k}+(P D I)_{i j l}+(P S I)_{i k l}+(D S I)_{j k l}+\varepsilon_{i j k} \\
\frac{\sigma_{p e r s o n}^{2}+\frac{\sigma_{p * d}^{2}}{n_{d}}+\frac{\sigma_{p * s}^{2}}{n_{S}}+\frac{\sigma_{p * i}^{2}}{n_{i}}+\frac{\sigma_{p * d * s}^{2}}{n_{d} n_{s}}+\frac{\sigma_{p * d * i}^{2}}{n_{d} n_{i}}+\frac{\sigma_{p * s * i}^{2}}{n_{s} n_{i}}+\frac{\sigma_{r e s i d u a l}^{2}}{n_{d} n_{s} n_{i}}}{\frac{\sigma_{p * d * s}^{2}}{\sigma_{p * d * s}^{2}+\frac{\sigma_{r e s i d u a l}^{2}}{n_{i}}}}
\end{gathered}
$$

After obtaining variance components and reliability coefficients, we moved on to build four types of multilevel models to answer more substantial research questions. First, for each variable, a simplified multilevel null model was built to serve as the baseline model, with only person and person by day-of-week interaction as grouping variables in the model (model 1, see Equation 5$)^{8}$.

\footnotetext{
${ }^{8}$ Simplification was made for two reasons: (1) variance components of day-of-week $\left(\sigma_{\text {day-of-week }}\right)$ and day-ofweek by session $\left(\sigma_{d * s}\right)$ were very small (see Section 3.2); (2) time variables $\sin T_{i j k}$ and $\cos T_{i j k}$ would correlate highly with session number and person by session as grouping variables.
} 


$$
Y_{i j k}=\beta_{0}+P_{i}+(P D)_{i j}+\varepsilon_{i j k}
$$

Secondly, a cosinor fitting procedure (e.g., Hasler et al., 2008; Murray et al., 2009) was used to model the diurnal pattern of state self-control capacity and core affect. The basic idea was to estimate how much variance of a variable can be explained by fitting sinusoids to the data. Technically, for each variable, a random-intercept model (model 2) was fitted by adding a sine component $\left(\sin T_{i j k}\right)$ and a cosine component $\left(\cos T_{i j k}\right)$ to the null model defined in Equation 5. The sine and cosine components were computed from the time variable $\left(T_{i j k}\right.$ in hours after midnight, e.g., 10.5 for 10:30) as in Equation 7 and 8.

$$
\begin{gathered}
Y_{i j k}=\beta_{0}+P_{i}+(P D)_{i j}+\beta_{1} \sin T_{i j k}+\beta_{2} \cos T_{i j k}+\varepsilon_{i j k} \\
\sin T_{i j k}=\sin \left(T_{i j k} \times 2 \pi / 24\right) \\
\cos T_{i j k}=\cos \left(T_{i j k} \times 2 \pi / 24\right)
\end{gathered}
$$

The improvement of model fit from model 1 to model 2 provides a measure of the strength of the diurnal pattern of modeled variables. The amplitude and phase angle of each fitted sinusoid can be calculated from $\beta_{1}$ and $\beta_{2}$ using Equation 9 and 10. Amplitude measures the maximum deviation of a variable from its mean so that a larger amplitude implies a stronger diurnal pattern, or in other words, larger cyclical fluctuations around the mean. Phase angle indicates at what time of day a variable shows its maximum deviation from the mean (peaks and valleys of the sinusoid).

$$
\begin{gathered}
\qquad A m p=\sqrt[2]{\beta_{1}^{2}+\beta_{2}^{2}} \\
\text { Phase shift }= \begin{cases}\tan ^{-1}\left(\beta_{1} / \beta_{2}\right)+\pi, & \text { IF } \beta_{2}<0 \\
\tan ^{-1}\left(\beta_{1} / \beta_{2}\right), & \text { IF } \beta_{2}>0 \text { AND } \beta_{1}>0 \\
\tan ^{-1}\left(\beta_{1} / \beta_{2}\right)+2 \pi, & \text { IF } \beta_{2}>0 \text { AND } \beta_{1}<0\end{cases}
\end{gathered}
$$

Thirdly, for each variable, a random-slope model (model 3) was fitted by allowing the 
coefficients of $\sin T_{i j k}$ and $\cos T_{i j k}$ to vary for different participants and for different days within participants, in order to explore variations in amplitude and phase angle at the personto-person and day-to-day levels (see Equation 11).

$$
\begin{gathered}
Y_{i j k}=\beta_{0}+P_{0 i}+(P D)_{0 i j}+\beta_{1} \sin T_{i j k}+\beta_{2} \cos T_{i j k}+P_{1 i} \sin T_{i j k}+(P D)_{1 i j} \sin T_{i j k} \\
+P_{2 i} \cos T_{i j k}+(P D)_{2 i j} \cos T_{i j k}+\varepsilon_{i j k}
\end{gathered}
$$

Finally, for examining the relationship between self-control capacity and dimensions of core affect, analyses were done using three different methods. To estimate the association between trait self-control and core affect, trait self-control was added as a person-level predictor in model 4. The effects were measured as $\beta_{3}$ (see Equation 12). Between-person and within-person correlations were estimated based on the data of state self-control capacity and core affect. The between-person component of each variable was estimated as $\beta_{0}$ in the corresponding random-slope models (Equation 11), and then Pearson correlation coefficients were computed based on the estimated person means. The within-person component of each variable was estimated as the residuals $\left(\varepsilon_{i j k}\right)$ in model 3 (Equation 11), and then Pearson correlation coefficients were computed based on the estimated within-person residuals. The within-person correlations estimated represented correlations between the momentary fluctuations of pairs of variables, after removing stable time-of-day effects.

$$
\begin{gathered}
Y_{i j k}=\beta_{0}+P_{0 i}+(P D)_{0 i j}+\beta_{1} \sin T_{i j k}+\beta_{2} \cos T_{i j k}+P_{1 i} \sin T_{i j k}+(P D)_{1 i j} \sin T_{i j k} \\
P_{2 i} \cos T_{i j k}+(P D)_{2 i j} \cos T_{i j k}+\beta_{3} T S C_{i}+\varepsilon_{i j k}
\end{gathered}
$$

All models were fitted using the package lme4 version 1.1-12 (Bates, Maechler, Bolker, \& Walker, 2015) in R programming environment $3.22^{9}$ (R Development Core Team, 2015).

\footnotetext{
${ }^{9}$ We also fitted a Bayesian version of all models by using the package "brms" version 1.10.0 (Bürkner, 2017), with order-1 autoregressive structure specified within the outcome variables. As results of the two approaches were almost identical, only results from the "lme4" package are reported. Code for the Bayesian models can be found in the scripts at the Open Science Framework.
} 


\section{Results}

\subsection{Respondent rates}

In Study 1, 4987 observations were collected from 140 participants. The mean response rate was $63.6 \%($ median $=69.6 \%, S D=23.8 \%)$. In Study 2, 5599 observations were collected from the 146 participants. The mean response rate was $68.5 \%$ (median $=75.0 \%, S D=$ $22.0 \%)^{10}$. Given that there was no monetary reward for the participants, the respondent rates were slightly lower than the ones in some other experience sampling studies $(77 \%$ in a metaanalysis, see Hofmann \& Patel, 2015), but they were still comparable to some studies with payment (e.g., Wilt, Funkhouser, \& Revelle, 2011). As we planned to estimate diurnal patterns in model 3 and model 4, a sufficient number of observations for different periods of the day were required. Therefore, participants with less than 5 observations in either the morning (06:00 - 12:00), afternoon (12:00 - 18:00), or evening (later than 18:00) were excluded, leaving us with 125 participants in Study 1 and 132 participants in Study 2 for the following analyses ${ }^{11}$.

\subsection{Descriptives, variance components, and reliability coefficients}

Table 1 to Table 3 summarize descriptive results of the data, including sample means, variance components, and derived reliability coefficients. According to the sample means, on average, participants were in positive mood, experienced low tense arousal or stress, and reported to have relatively high state self-control capacity (particularly for the willpower and urge control items). In general, interindividual difference $\left(\sigma_{\text {person }}^{2}\right)$ accounted for a sizable

\footnotetext{
${ }^{10}$ For each scheduled notification, only responses that were made within half an hour were included to avoid largely overlapping observations in time.

${ }^{11}$ Including the excluded participants did not change the results to any significant extent.
} 
portion of total variance for all variables (10-40\%), and its contribution was larger for three components of state self-control capacity (willpower, urge control, and motivation) and tense arousal (25-40\%) than for energetic arousal, sleepiness, and concentration (10-20\%). In contrast, there was no overall day-to-day variance $\left(\sigma_{\text {day-of-week }}^{2}\right)$, but person-specific day-today variation $\left(\sigma_{p * d}^{2}\right)$ did explain a small portion of total variance for each variable $(6-12 \%)$. This trend of was slightly more evident for core affect than for state self-control capacity. Moreover, overall and person-specific session-to-session variation accounted for about $10 \%$ of the total variance for sleepiness, around 3-5\% for energetic arousal, concentration, and motivation, but not for other variables. Finally, when within-person within-day momentary variations $\left(\sigma_{p * d * s}^{2}\right)$ were estimated for variables with multiple-item measures, they greatly reduced residual variance and accounted for about $15-40 \%$ of the total variance. Results also indicated that state self-control capacity had less momentary fluctuations than core affect.

In terms of reliability, between-person reliability was good for most measures, with generalizability coefficient ranging from 0.75 to 0.95 . If the goal is to determine the relative rank of participants' scores on core affect and state self-control capacity, single-item measures seem to be good enough in a typical experience sampling design since large number of observations were averaged (56 in our case). However, within-person reliability coefficients of change measured by $R_{c}$ were lower, ranging from acceptable for core affect (0.69 to 0.77 ) and insufficient for state self-control capacity (below 0.7). Although future research should increase the number of measurement items when possible to increase withinperson reliability, our results for within-person correlations between variables were unlikely to suffer from this issue because measurement errors of a pair of variables were independent in theory. Our analyses of reliability did raise questions on the validity of combining all four components of state self-control capacity to a total score (see Table 3), as evident by the low average alpha coefficients $\left(\alpha_{\text {ave }}\right)$, low reliability of change, as well as large percentages of 
total variance accounted by overall and person-specific item-to-item variations $\left(\sigma_{\text {item }}^{2}\right.$ and $\left.\sigma_{p * i}^{2}\right)$

\section{Insert Table 1}

\section{$\underline{\text { Insert Table } 2}$}

\section{$\underline{\text { Insert Table } 3}$}

\subsection{Modeling diurnal patterns in state self-control and affective states}

Adding the time variables $\left(\sin T_{i j k}\right.$ and $\left.\cos T_{i j k}\right)$ into the models (from model 1 to model 2) significantly improved model fit for all state measures $(p<.0001$ in all Chi-square tests), indicating some degree of diurnal patterns in the temporal variations of state selfcontrol capacity and core affect. Table 4 summarizes the results of the random-intercept models (model 2) and the random-slope models (model 3). An increase in pseudo $R^{2}$ indicates an improved model fit by adding the time variables as predictors (model 2), or by further allowing the coefficients for the time variables to vary between participants and between days within each participant (model 3) ${ }^{12}$. Among the four state self-control components, concentration had a stronger diurnal pattern than the other three components, and according to the phase angle estimates, concentration level on average peaked at around 13:30 - 14:00 for the student participants. It was also interesting to observe that the peak of urge control happened in the late morning (around 10:30), while all the other components of state selfcontrol capacity peaked in the early afternoon (13:00 - 14:30). However, as the diurnal patterns for urge control and willpower were very weak, the estimated phase angles should be interpreted with caution. Among the dimensions of core affect, sleepiness had the strongest diurnal pattern, followed by energetic arousal, while valence and tense arousal had very weak

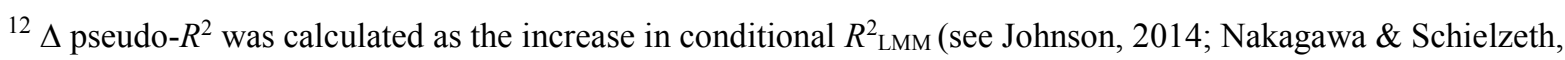
2013) from the null models (model 1) to the random-intercept models (model 2), and to the random-slope models (model 3). The calculations were done using the piecewiseSEM package in R (Lefcheck, 2015).
} 
patterns. According to the phase angle estimates, participants were happiest in the evening (cf. Kahneman, Krueger, Schkade, Schwarz, \& Stone, 2004), most stressed in the early afternoon (around 13:00), most vital at around 15:00, and sleepiest at around 3:00.

\section{$\underline{\text { Insert Table } 4}$}

\subsection{Effects of trait self-control on affective states and state self-control capacity}

The effects of trait self-control on affective states were estimated as the parameter $\beta_{3}$ (standardized regression coefficient) in model 4. As expected, trait self-control seemed to positively correlate with valence across both studies (see Figure 1; for all graphical representations of the results, see Supplementary Material), although the effects were quite small and nonsignificant in the individual studies (Study 1: $\beta=0.07,95 \% \mathrm{CI}=[-0.01,0.16]$, $p=.097, r=0.13^{13} ;$ Study 2: $\left.\beta=0.08,95 \% \mathrm{CI}=[-0.01,0.16], p=.090, r=0.11\right)$. Moreover, trait self-control was correlated to tense arousal in the studies (see Figure 1), meaning that students with higher trait self-control experienced, on average, less tension or stress during the sampling week (Study 1: $\beta=-0.14,95 \% \mathrm{CI}=[-0.24,-0.05], p=.005, r=-0.24$; Study 2: $\beta=-0.15,95 \% \mathrm{CI}=[-0.26,-0.04], p=.009, r=-0.22)$. However, in both studies, trait selfcontrol did not significantly correlate with energetic arousal (Study 1: $\beta=0.02,95 \% \mathrm{CI}=[-$ $0.05,0.10], p=0.57$; Study $2: \beta=0.05,95 \% \mathrm{CI}=[-0.03,0.13], p=.24)$ nor sleepiness (Study 1: $\beta=-0.04,95 \% \mathrm{CI}=[-0.11,0.02], p=.20$; Study $2: \beta=-0.05,95 \% \mathrm{CI}=[-0.13$, $0.03], p=.24)$.

\section{$\underline{\text { Insert Figure } 1}$}

We also examined the relationship between trait self-control and state self-control

\footnotetext{
${ }^{13}$ The $r$ henceforth, as an effect-size measure, was calculated as the correlational strength between trait selfcontrol and the between-person components of the state variables. It provides a way to compare our data with the effect sizes in previous studies with different data structures.
} 
capacity in the same way. Results revealed reliable positive correlations between trait selfcontrol and three components of state self-control capacity, including concentration (Study 1: $\beta=0.15,95 \% \mathrm{CI}=[0.08,0.23], p<.001, r=0.28$; Study $2: \beta=0.16,95 \% \mathrm{CI}=[0.08,0.23]$, $p<.001, r=0.31$ ), willpower (Study 1: $\beta=0.18,95 \% \mathrm{CI}=[0.08,0.28], p<.001, r=0.28$; Study 2: $\beta=0.25,95 \% \mathrm{CI}=[0.16,0.34], p<.001, r=0.41)$, urge control (Study 1: $\beta=0.25$, $95 \% \mathrm{CI}=[0.15,0.35], p<.001, r=0.39$; Study $2: \beta=0.26,95 \% \mathrm{CI}=[0.17,035], p<.001$, $r=0.48)$. For motivation, the results were inconsistent across the two studies - trait selfcontrol had a small positive effect on motivation in Study $2(\beta=0.12,95 \% \mathrm{CI}=[0.02,0.23]$, $p=.027, r=0.19)$, but not in Study $1(\beta=0.005,95 \% \mathrm{CI}=[-0.09,0.10], p=.92, r=0.01)$. The inconsistency might be due to the change in the phrasing of the item between the two studies - emphasizing long-term goals better matched the conceptualization of self-control in the Brief Trait Self-Control Scale (see measurement section for details).

\subsection{Between and within-person correlations between state self-control and affective states}

Table 5 and Table 6 summarizes between-person and within-person correlations between pairs of state measures used in the two studies respectively. For understanding the relationship between two variables, a between-person correlation reflects the accumulated association over time at person-level, indicating whether a person scoring high on one variable tends to score high or low on the other variable. In contrast, a within-person correlation indicates whether two variables tend to deviate from personal means at the same time. Overall, results showed a clear pattern that between-person correlations were generally stronger than within-person correlations.

In the cluster of core affect (top-left of the tables), the within-person correlations in general supported the valence-arousal model of core affect (Russell \& Barrett, 1999): Weak or no correlation between the orthogonal dimensions (valence-arousal, energetic arousaltense arousal), and moderate correlations in the expected directions between the adjacent 
dimensions (valence-energetic arousal, valence-tense arousal, and energetic arousalsleepiness). However, inconsistent with valence-arousal model, a negative correlation between tense arousal and sleepiness (or positive correlation between tense arousal and pure arousal) was not found.

In the state self-control cluster (bottom-right), it was interesting to observe that the motivation component only correlated very weakly with the other three highly correlated components at the between-person level, but it did correlate strongly with them at the withinperson level. In other words, participants' average levels of motivation were largely independent from the other components, but they tended to have stronger motivation at the time when they had more willpower, could concentrate well, and control their urges.

\section{Insert Table 5}

\section{$\underline{\text { Insert Table } 6}$}

The relationship between state self-control capacity and core affect is shown in the leftbottom of the two tables. At the between-person level (Table 5), participants with higher average self-control capacity were also happier, more energetic, less stressed, and less sleepy on average. These results were in line with the correlations of trait self-control and these dimensions of core affect. However, the motivation component of self-control correlated strongly with energetic arousal and sleepiness, weakly with valence, but was independent from tense arousal. When within-person correlations were examined (Table 6), it was intriguing to observe that state self-control's correlations with valence shrank, and the correlation with stress disappeared almost completely. In contrast, its relationship with energetic arousal and sleepiness remained at the same level, with even a small increase for the motivation component. 


\section{Discussion}

In two experience sampling studies, we studied the variation of self-control capacity among university students in their daily lives. Using a multilevel modeling approach and the cosinor fitting method, we were able to quantify the variation of self-control capacity at different levels of interests, and to model its temporal variation as diurnal patterns. Moreover, we systematically examined the relationship between self-control capacity and core affect, in order to facilitate better theorization of self-control capacity as a construct. With two large group of participants and time-intensive repeated measures, results were quite consistent across the two studies and are likely to be robust, at least for similar student samples in similar contexts.

The first set of findings simply characterizes the variability of self-control capacity. Compared with valence, pure arousal (sleepiness), and energetic arousal, self-control capacity seems to differ more strongly between participants (approximately one-third of the total variance is due to between-subject factors). Although numerous studies have suggested a stable trait difference in the ability of self-control (de Ridder et al., 2012), our results provide the first quantitative information about the percentage of the interindividual difference in comparison with other psychological states. Even though the absolute percentage estimation could have been inflated by response style differences between participants, the relative ranking suggests that interindividual difference is more stable for self-control capacity than for core affect. In contrast, intraindividual day-to-day variation of self-control capacity is quite small in our data, despite common folk psychological beliefs (e.g., people often talk about having days in which they are able to control themselves better or worse, see Bergen, 2011). In fact, among all variables measured, state self-control components had the smallest day-to-day variations (all less than $9 \%$ of the total variance). Similarly, as estimated using the 4-item composite scale, self-control capacity also appears to have smaller intraindividual 
variation from moment to moment (around 15\%), when compared to the momentary variation in core affect (30-40\%). For the concentration and motivation components of self-control capacity, a small portion of their variations can be modeled as diurnal patterns. A typical student's ability to concentrate, and their motivation to pursue important goals, seems to increase after awakening, reach a peak at around 13:00 in the afternoon, and then decrease till sleep time. This mirrors the time-of-day pattern of learning performance in Randle et al. (2017), where performance also peaked early in the afternoon. Nonetheless, these time-of-day effects are only small parts of their temporal variations, which may otherwise be influenced by contextual factors (e.g., their physical and social environment, ongoing activities, etc.). Future experience sampling studies should attempt to measure contextual factors in people's daily lives.

A second contribution of our studies is the systematic examination of the relationship between self-control and core affect. When self-control is measured at trait level, our results corroborate previous studies on the associations of trait self-control with affective valence and tense arousal (Bowlin \& Baer, 2012; Daly et al., 2014; Galla \& Wood, 2015; Hofmann et al., 2014). Although the effect on valence was estimated to be small and nonsignificant, we can reject a null-effect if we combine the data across the studies meta-analytically (see Figure 2). One reason for the smaller effect sizes in our studies $(r=0.14$ and $r=0.11)$ compared with the ones in earlier studies (meta-analytic $r=0.26$ ) might be that we used bipolar measures of valence while other studies mostly used unipolar scales selected from PANAS (Watson, Clark, \& Tellegen, 1988). The bipolar items we used (e.g., happy-sad, pleasantunpleasant) measure only the valence dimension, whereas the unipolar scales of positive affect sometimes also include items related to tense arousal, such as calm, which might have biased effect sizes in those studies. Regardless of the different conceptualizations and measurements of affective valence, when evaluated based on all available data, we can 
conclude that a small positive association between trait self-control and valence is reliable and robust in different populations. For tense arousal, our data provide the first clear evidence using an experience sampling design that people with higher trait self-control are likely to experience less psychological stress in daily lives, complementing evidence obtained using a one-time survey (Bowlin \& Baer, 2012) and a daily diary method (Galla \& Wood, 2015). The effect sizes of correlation between trait self-control and tense arousal are similar to those observed in earlier studies (see Figure 3).

Insert Figure 2

Insert Figure 3

In addition, by measuring state self-control capacity multiple times for multiple days, we could model the relationship between self-control capacity and core affect as both between-person and within-person correlations. The estimated between-person correlations between self-control capacity and core affect are in line with the results at the trait level, but with larger effect sizes (e.g., an increase of $r$ from around 0.2 to 0.4 for sleepiness). The larger effect sizes may be explained by the fact that state measures of both self-control capacity and core affect are constrained by participants' experience in the week of the studies, while the trait self-control scale measures people's retrospective beliefs about their abilities based on broader past experience. However, as state measures of all variables were contingent to each other in each experience sampling session and were in similar formats, the between-person correlations might have been inflated by individual differences in response styles (e.g., some participants tended to rate all scales more extremely). When the betweenperson components and structural time-of-day effects are accounted for, the residual correlations at a within-person level reflect the genuine intraindividual relationship between self-control capacity and core affect. Intraindividually, it is clear that a person's self-control 
capacity changes together with their level of alertness and vitality. When someone is alert and energetic, they are likely better able to concentrate, to control urges, and to pursue long-term goals. Surprisingly, results suggest no correlation between self-control capacity and tense arousal at the within-person level, even though interindividually the correlation seems to be robust (see Figure 3). Despite the evidence that acute stress elicited experimentally can impede self-control process (Maier et al., 2015), the natural variation of stress and selfcontrol capacity may not be strongly related in people's daily lives. This conclusion should be treated with caution, given the uncontrolled factors in our experience sampling design and the limited measurement reliability.

Another intriguing finding, for which we currently see no clear theoretical explanation, was that the motivation component of state self-control capacity did not correlate with concentration, willpower, and urge-control at between-person level, but did correlate strongly with these components intraindividually. According to self-control models from a dualsystem perspective (Hofmann et al., 2009; Kotabe \& Hofmann, 2015), it might be that the motivation item captured the dynamics of control motivation in the exertion cluster, whereas the willpower and urge-control items captured desire strength in the activation cluster. Moreover, our finding that motivation is distinct from willpower and urge-control seems to complement recent work that implies an overarching control role of motivation in self-control processes (Milyavskaya, Inzlicht, Hope, \& Koestner, 2015). Given the seemingly deviating result for motivation, future work should particularly explore the role of motivation in selfcontrol processes.

Our studies have important implications for the conceptualization of state self-control capacity, and how this construct should be measured. By positioning self-control capacity in a nomological network with dimensions of core affect, it becomes clear that the state variation of self-control capacity cannot be fully explained by the variation in core affect. 
This distinction is consistent with results from the ego-depletion paradigm in that changes in self-control capacity are generally not mirrored by changes in positive and negative affect (e.g., Muraven et al., 1998), and the distinction also extends to feelings of arousal and vitality. Although our results are far from resolving the theoretical debate about the causal role of self-control capacity, they do suggest that self-control capacity may provide additional explanatory power, above and beyond variation in core affect. This tentative conclusion could be strengthened if future studies using behavioral measures of self-control outcomes would conceptually replicate these results. For such studies to be successful, other potential determinants of self-control outcomes need to be carefully controlled, including task factors (e.g., attractiveness of immediate rewards) as well as control motivation as a different person factor (cf. Kotabe \& Hofmann, 2015).

On the other hand, our results cast further doubt on the view that self-control capacity is a unified finite resource (see also Randle et al., 2017). At the very least, results suggest that the concentration and motivation components of state self-control capacity are two subconstructs that are distinct from a third sub-construct as measured by the willpower and urgecontrol items. With the temporal richness of experience sampling data, the distinctions are made based not only on the pattern of between-person correlations, but also on the pattern of within-person correlations and the temporal characteristics of the measured items. For future research, instead of treating state self-control capacity as a unified construct, a more fruitful approach might be to examine concrete sub-constructs of self-control capacity and to study how each of these sub-constructs influences self-control outcomes. For measuring the subconstructs, we would recommend using 2-3 items for each construct based our reliability analyses, in order to achieve sufficient within-person reliability. Following the network perspective of psychometrics, these sub-constructs can be treated as real psychological entities that are causally linked (e.g., bad concentration may make controlling urges more 
difficult), rather than as measurement items that are causally determined by one single construct called self-control capacity, as in the traditional latent variable approach (for network perspectives on other psychological constructs, see e.g., Costantini et al., 2015; Schmittmann et al., 2011).

Overall, we hope that our studies have provided useful descriptive data to facilitate theory generation in self-control research, especially regarding the theoretical status of control capacity, and a stimulating example of how to examine within-person processes of self-control capacity using the experience sampling method. 


\section{References}

Åkerstedt, T., \& Gillberg, M. (1990). Subjective and objective sleepiness in the active individual. International Journal of Neuroscience, 52, 29-37. http://dx.doi.org/10.3109/00207459008994241

Bates, D., Maechler, M., Bolker B., \& Walker, S. (2015). Fitting linear mixed-effects models using lme4. Journal of Statistical Software, 67, 1-48. doi:10.18637/jss.v067.i01.

Baumeister, R. F., \& Heatherton, T. F. (1996). Self-regulation failure: An overview. Psychological Inquiry, 7, 1-15. http://dx.doi.org/10.1207/s15327965pli0701_1

Baumeister, R. F., Vohs, K. D., \& Tice, D. M. (2007). The strength model of self-control. Current Directions in Psychological Science, 16, 351-355. https://doi.org/10.1111/j.1467-8721.2007.00534.x

Bergen, A. E. (2011). Self-control in context: A mixed methods investigation of self-control and self-control failure. PhD dissertation. The University of Guelph.

Bowlin, S. L., \& Baer, R. A. (2012). Relationships between mindfulness, self-control, and psychological functioning. Personality and Individual Differences, 52, 411-415. http://dx.doi.org/10.1016/j.paid.2011.10.050

Bürkner, P. C. (2017). brms: An R package for Bayesian multilevel models using Stan. Journal of Statistical Software, 80. doi: 10.18637/jss.v080.i01

Carter, E. C., Kofler, L. M., Forster, D. E., \& McCullough, M. E. (2015). A series of metaanalytic tests of the depletion effect: Self-control does not seem to rely on a limited resource. Journal of Experimental Psychology: General, 144, 796-815. http://dx.doi.org/10.1037/xge0000083

Carver, C. S., \& Scheier, M. F. (1990). Origins and functions of positive and negative affect: A control-process view. Psychological Review, 97, 19-35. 
Ciarocco, N. J., Twenge, J. M., Muraven, M., \& Tice, D. M. (2015). The State Self-Control Capacity Scale: Reliability, validity, and correlations with physical and psychological stress. Manuscript under revision.

Costantini, G., Epskamp, S., Borsboom, D., Perugini, M., Mõttus, R., Waldorp, L. J., \& Cramer, A. O. (2015). State of the aRt personality research: A tutorial on network analysis of personality data in R. Journal of Research in Personality, 54, 13-29. https://doi.org/10.1016/j.jrp.2014.07.003

Cranford, J. A., Shrout, P. E., Iida, M., Rafaeli, E., Yip, T., \& Bolger, N. (2006). A procedure for evaluating sensitivity to within-person change: Can mood measures in diary studies detect change reliably?. Personality and Social Psychology Bulletin, 32, 917-929. https://doi.org/10.1177/0146167206287721

Crescioni, A. W., Ehrlinger, J., Alquist, J. L., Conlon, K. E., Baumeister, R. F., Schatschneider, C., \& Dutton, G. R. (2011). High trait self-control predicts positive health behaviors and success in weight loss. Journal of Health Psychology, 16, 750759. doi: $10.1177 / 1359105310390247$

Cronbach, I. J., Gleser, G. C., Nanda, H., \& Rajaratnam, N. (1972). The dependability of behavioral measurements: Theory of generalizability for scores and profiles. New York: John Wiley.

Cronbach, L. J., \& Meehl, P. E. (1955). Construct validity in psychological tests. Psychological Bulletin, 52, 281-302. http://dx.doi.org/10.1037/h0040957

Curran, P. J., \& Bauer, D. J. (2011). The disaggregation of within-person and between-person effects in longitudinal models of change. Annual Review of Psychology, 62, 583-619. doi: 10.1146/annurev.psych.093008.100356. 
Daly, M., Baumeister, R. F., Delaney, L., \& MacLachlan, M. (2014). Self-control and its relation to emotions and psychobiology: Evidence from a Day Reconstruction Method study. Journal of Behavioral Medicine, 37, 81-93. doi:10.1007/s10865-012-9470-9

de Ridder, D. T., Lensvelt-Mulders, G., Finkenauer, C., Stok, F. M., \& Baumeister, R. F. (2012). Taking stock of self-control: A meta-analysis of how trait self-control relates to a wide range of behaviors. Personality and Social Psychology Review, 16, 76-99. doi: $10.1177 / 1088868311418749$

Duckworth, A. L. (2011). The significance of self-control. Proceedings of the National Academy of Sciences, 108, 2639-2640. doi: 10.1073/pnas.1019725108

Duckworth, A. L., \& Seligman, M. E. (2005). Self-discipline outdoes IQ in predicting academic performance of adolescents. Psychological Science, 16, 939-944. doi: 10.1111/j.1467-9280.2005.01641.x

Etherton, J. L., Osborne, R., Stephenson, K., Grace, M., Jones, C., \& De Nadai, A. (2018). Bayesian analysis of multimethod ego- depletion studies favours the null hypothesis. British Journal of Social Psychology. doi: 10.1111/bjso.12236

Gailliot, M. T., Baumeister, R. F., DeWall, C. N., Maner, J. K., Plant, E. A., Tice, D. M., ... \& Schmeichel, B. J. (2007). Self-control relies on glucose as a limited energy source: willpower is more than a metaphor. Journal of Personality and Social Psychology, 92, 325-336. http://dx.doi.org/10.1037/0022-3514.92.2.325

Galla, B. M., \& Wood, J. J. (2015). Trait Self-Control Predicts Adolescents' Exposure and Reactivity to Daily Stressful Events. Journal of Personality, 83, 69-83. doi: 10.1111/jopy.12083

Hall, P. A., \& Fong, G. T. (2007). Temporal self-regulation theory: A model for individual health behavior. Health Psychology Review, 1, 6-52. https://doi.org/10.1080/17437190701492437 
Hasler, B. P., Mehl, M. R., Bootzin, R. R., \& Vazire, S. (2008). Preliminary evidence of diurnal rhythms in everyday behaviors associated with positive affect. Journal of Research in Personality, 42, 1537-1546. http://dx.doi.org/10.1016/j.jrp.2008.07.012

Hofmann, W., Gschwendner, T., Friese, M., Wiers, R. W., \& Schmitt, M. (2008). Working memory capacity and self-regulatory behavior: Toward an individual differences perspective on behavior determination by automatic versus controlled processes. Journal of Personality and Social Psychology, 95, 962-77. http://dx.doi.org/10.1037/a0012705

Hofmann, W., Luhmann, M., Fisher, R. R., Vohs, K. D., \& Baumeister, R. F. (2014). Yes, but are they happy? Effects of trait self-control on affective well-being and life satisfaction. Journal of Personality, 82, 265-277. doi: 10.1111/jopy.12050

Hofmann, W., \& Patel, P. V. (2015). SurveySignal: A convenient solution for experience sampling research using participants' own smartphones. Social Science Computer Review, 33, 235-253. doi: 10.1177/0894439314525117

Hur, J. D., Koo, M., \& Hofmann, W. (2015). When temptations come alive: How anthropomorphism undermines self-control. Journal of Consumer Research, 42, 340358. https://doi.org/10.1093/jcr/ucv017

Inzlicht, M., Bartholow, B. D., \& Hirsh, J. B. (2015). Emotional foundations of cognitive control. Trends in Cognitive Sciences, 19, 126-132. https://doi.org/10.1016/j.tics.2015.01.004

Inzlicht, M., \& Berkman, E. (2015). Six questions for the resource model of control (and some answers). Social and Personality Psychology Compass, 9, 511-524. doi: $10.1111 / \mathrm{spc} 3.12200$ 
Inzlicht, M., \& Schmeichel, B. J. (2012). What is ego depletion? Toward a mechanistic revision of the resource model of self-control. Perspectives on Psychological Science, 7, 450-463. https://doi.org/10.1177/1745691612454134

Inzlicht, M., Schmeichel, B. J., \& Macrae, C. N. (2014). Why self-control seems (but may not be) limited. Trends in Cognitive Sciences, 18, 127-133. https://doi.org/10.1016/j.tics.2013.12.009

Johnson, P. C. (2014). Extension of Nakagawa \& Schielzeth's $R^{2}{ }_{\text {GLMM }}$ to random slopes models. Methods in Ecology and Evolution, 5, 944-946. doi: 10.1111/2041210X.12225

Kahneman, D., Krueger, A. B., Schkade, D. A., Schwarz, N., \& Stone, A. A. (2004). A survey method for characterizing daily life experience: The day reconstruction method. Science, 306, 1776-1780. doi: 10.1126/science.1103572

Kanfer, F. H., \& Karoly, P. (1972). Self-control: A behavioristic excursion into the lion's den. Behavior Therapy, 3, 398-416. https://doi.org/10.1016/S0005-7894(72)80140-0

Kotabe, H. P., \& Hofmann, W. (2015). On integrating the components of self-control. Perspectives on Psychological Science, 10, 618-638. https://doi.org/10.1177/1745691615593382

Kurzban, R. (2012). Why everyone (else) is a hypocrite: Evolution and the modular mind. Princeton University Press.

Lefcheck, J. S. (2016). piecewiseSEM: Piecewise structural equation modelling in $r$ for ecology, evolution, and systematics. Methods in Ecology and Evolution, 7, 573-579. doi: $10.1111 / 2041-210 X .12512$

Loewenstein, G. (2000). Willpower: A decision-theorist's perspective. Law and Philosophy, 19, 51-76. doi:10.1023/A:1006372420490 
Maier, S. U., Makwana, A. B., \& Hare, T. A. (2015). Acute stress impairs self-control in goal-directed choice by altering multiple functional connections within the brain's decision circuits. Neuron, 87, 621-631. http://dx.doi.org/10.1016/j.neuron.2015.07.005 Milyavskaya, M., Inzlicht, M., Hope, N., \& Koestner, R. (2015). Saying “no” to temptation: Want-to motivation improves self-regulation by reducing temptation rather than by increasing self-control. Journal of Personality and Social Psychology, 109, 677-93. doi: $10.1037 /$ pspp0000045

Mischel, W., Shoda, Y., \& Peake, P. K. (1988). The nature of adolescent competencies predicted by preschool delay of gratification. Journal of Personality and Social Psychology, 54, 687- 696. http://dx.doi.org/10.1037/0022-3514.54.4.687

Mischel, W., Shoda, Y., \& Rodriguez, M. L. (1989). Delay of gratification in children. Science, 244, 933-938.

Moffitt, T. E., Arseneault, L., Belsky, D., Dickson, N., Hancox, R. J., Harrington, H., ... \& Sears, M. R. (2011). A gradient of childhood self-control predicts health, wealth, and public safety. Proceedings of the National Academy of Sciences, 108, 2693-2698. doi: 10.1073/pnas.1010076108

Muraven, M., Tice, D. M., \& Baumeister, R. F. (1998). Self-control as a limited resource: Regulatory depletion patterns. Journal of Personality and Social Psychology, 74, 774789.

Murray, G., Nicholas, C. L., Kleiman, J., Dwyer, R., Carrington, M. J., Allen, N. B., \& Trinder, J. (2009). Nature's clocks and human mood: The circadian system modulates reward motivation. Emotion, 9, 705-716. doi: 10.1037/a0017080

Nakagawa, S., \& Schielzeth, H. (2013). A general and simple method for obtaining R2 from generalized linear mixed-effects models. Methods in Ecology and Evolution, 4, 133 142. doi: 10.1111/j.2041-210x.2012.00261.x 
Navon, D. (1984). Resources-A theoretical soup stone?. Psychological Review, 91, 216234. http://dx.doi.org/10.1037/0033-295X.91.2.216

Pessoa, L. (2009). How do emotion and motivation direct executive control?. Trends in Cognitive Sciences, 13, 160-166. https://doi.org/10.1016/j.tics.2009.01.006

R Development Core Team (2008). R: A language and environment for statistical computing. R Foundation for Statistical Computing, Vienna, Austria. ISBN 3-900051-07-0, URL http://www.R-project.org.

Randles, D., Harlow, I., \& Inzlicht, M. (2017). A pre-registered naturalistic observation of within domain mental fatigue and domain-general depletion of self-control. PLoS One, 12, e0182980. https://doi.org/10.1371/journal.pone.0182980

Robinson, M. D., Schmeichel, B. J., \& Inzlicht, M. (2010). A cognitive control perspective of self- control strength and its depletion. Social and Personality Psychology Compass, 4, 189-200. doi: 10.1111/j.1751-9004.2009.00244.x

Russell, J. A. (2003). Core affect and the psychological construction of emotion. Psychological Review, 110, 145-172. http://dx.doi.org/10.1037/0033-295X.110.1.145

Russell, J. A., \& Barrett, L. F. (1999). Core affect, prototypical emotional episodes, and other things called emotion: Dissecting the elephant. Journal of Personality and Social Psychology, 76, 805-819. http://dx.doi.org/10.1037/0022-3514.76.5.805.

Russell, J. A., \& Carroll, J. M. (1999). On the bipolarity of positive and negative affect. Psychological Bulletin, 125, 3-30. doi: 10.1037/0033-2909.125.1.3

Saunders, B., \& Inzlicht, M. (2018). An appraisal framework to understand why negative affect is both good and bad for self-control. PsyArXiv Preprints. https://psyarxiv.com/3d $8 \mathrm{fk} /$

Schimmack, U. (2003). Affect measurement in experience sampling research. Journal of Happiness Studies, 4, 79-106. doi:10.1023/A:1023661322862 
Schmittmann, V. D., Cramer, A. O., Waldorp, L. J., Epskamp, S., Kievit, R. A., \& Borsboom, D. (2013). Deconstructing the construct: A network perspective on psychological phenomena. New Ideas in Psychology, 31, 43-53. https://doi.org/10.1016/j.newideapsych.2011.02.007

Shrout, P. E., \& Lane, S. P. (2011). Psychometrics. In M. R. Mehl, \& T. A. Conner (Eds.), Handbook of research methods for studying daily life (pp. 302-320). New York, NY: Guilford Press.

Smolders, K. C. H. J., De Kort, Y. A. W., \& Van den Berg, S. M. (2013). Daytime light exposure and feelings of vitality: Results of a field study during regular weekdays. Journal of Environmental Psychology, 36, 270-279. http://dx.doi.org/10.1016/j.jenvp.2013.09.004

Stone, A. A., Schwartz, J. E., Schkade, D., Schwarz, N., Krueger, A., \& Kahneman, D. (2006). A population approach to the study of emotion: Diurnal rhythms of a working day examined with the Day Reconstruction Method. Emotion, 6, 134-139. http://dx.doi.org/10.1037/1528-3542.6.1.139

Strauss, M. E., \& Smith, G. T. (2009). Construct validity: Advances in theory and methodology. Annual Review of Clinical Psychology, 5, 1-25. https://doi.org/10.1146/annurev.clinpsy.032408.153639

Tangney, J. P., Baumeister, R. F., \& Boone, A. L. (2004). High self-control predicts good adjustment, less pathology, better grades, and interpersonal success. Journal of Personality, 72, 271-324. doi: 10.1111/j.0022-3506.2004.00263.x

Thai, S. \& Page-Gould, E. (2017). ExperienceSampler: An open-source scaffold for building smartphone apps for experience sampling. Psychological Methods. Online first publication. 
Thomas, M., Sing, H., Belenky, G., Holcomb, H., Mayberg, H., Dannals, R., ... \& Welsh, A. (2000). Neural basis of alertness and cognitive performance impairments during sleepiness. I. Effects of $24 \mathrm{~h}$ of sleep deprivation on waking human regional brain activity. Journal of Sleep Research, 9, 335-352. doi: 10.1046/j.13652869.2000.00225.x

Watson, D., Clark, L. A., \& Tellegen, A. (1988). Development and validation of brief measures of positive and negative affect: The PANAS scales. Journal of Personality and Social Psychology, 54, 1063-1070. http://dx.doi.org/10.1037/0022-3514.54.6.1063

Webb, N. M., Shavelson, R. J., \& Haertel, E. H. (2006). 4 reliability coefficients and generalizability theory. Handbook of Statistics, 26, 81-124. https://doi.org/10.1016/S0169-7161(06)26004-8

Wilt, J., Funkhouser, K., \& Revelle, W. (2011). The dynamic relationships of affective synchrony to perceptions of situations. Journal of Research in Personality, 45, 309321. http://dx.doi.org/10.1016/j.jrp.2011.03.005

Wood, C., \& Magnello, M. E. (1992). Diurnal changes in perceptions of energy and mood. Journal of the Royal Society of Medicine, 85, 191-194. 
Table 1. Means, variance components, and reliability coefficients for core affect

\begin{tabular}{|c|c|c|c|c|c|c|c|c|}
\hline & Valence & $\%$ & EA & $\%$ & TA & $\%$ & Sleepiness & $\%$ \\
\hline$\sigma_{\text {person }}^{2}$ & $0.31 / 0.25$ & $20.7 / 17.6$ & $0.28 / 0.24$ & $15.0 / 12.1$ & $0.61 / 0.50$ & $30.6 / 24.9$ & $0.32 / 0.58$ & $11.0 / 18.0$ \\
\hline$\sigma_{\text {day-of-week }}^{2}$ & $0.02 / 0.01$ & $1.2 / 0.4$ & $0.02 / 0.02$ & $0.9 / 0.8$ & $0.03 / 0.01$ & $1.6 / 0.5$ & $0.02 / 0.03$ & $0.6 / 0.8$ \\
\hline$\sigma_{\text {session }}^{2}$ & $0.03 / 0.01$ & $1.9 / 1.0$ & $0.08 / 0.06$ & $4.1 / 3.2$ & $0.02 / 0.01$ & $0.8 / 0.6$ & $0.32 / 0.25$ & $10.9 / 7.9$ \\
\hline$\sigma_{i t e m}^{2}$ & $-/ 0.00$ & $-/ 0$ & $-/ 0.00$ & $-/ 0.2$ & $-/ 0.01$ & $-/ 0.5$ & $-1-$ & $-1-$ \\
\hline$\sigma_{p * d}^{2}$ & $0.18 / 0.11$ & $11.9 / 7.7$ & $0.19 / 0.14$ & $10.4 / 7.4$ & $0.23 / 0.16$ & $11.7 / 7.7$ & $0.31 / 0.27$ & $10.4 / 8.5$ \\
\hline$\sigma_{p * S}^{2}$ & $0.02 / 0.02$ & $1.2 / 1.2$ & $0.07 / 0.10$ & $4.0 / 5.0$ & $0.02 / 0.03$ & $0.9 / 1.7$ & $0.20 / 0.29$ & 6.9 / 8.9 \\
\hline$\sigma_{p * i}^{2}$ & $-/ 0.03$ & $-/ 2.2$ & $-/ 0.03$ & $-/ 1.8$ & $-/ 0.05$ & $-/ 2.4$ & $0.03 / 0.04$ & $0.9 / 1.3$ \\
\hline$\sigma_{d * s}^{2}$ & $0.01 / 0.01$ & $0.5 / 0.6$ & $0.02 / 0.02$ & $1.2 / 0.9$ & $0.00 / 0.01$ & $0.2 / 0.4$ & $-1-$ & $-1-$ \\
\hline$\sigma_{d * i}^{2}$ & $-/ 0.00$ & $-/ 0$ & $-/ 0.00$ & $-/ 0$ & $-/ 0.00$ & $-/ 0.2$ & $-1-$ & $-1-$ \\
\hline$\sigma_{s * i}^{2}$ & $-/ 0.00$ & $-/ 0$ & $-/ 0.00$ & $-/ 0$ & $-/ 0.00$ & -0 & $-1-$ & $-1-$ \\
\hline$\sigma_{p * d * s}^{2}$ & $-/ 0.62$ & $-/ 43.3$ & $-/ 0.69$ & $-/ 35.6$ & $-/ 0.58$ & $-/ 29.0$ & $-1-$ & $-1-$ \\
\hline$\sigma_{p * d * i}^{2}$ & $-/ 0.00$ & $-/ 0.2$ & $-/ 0.03$ & $-/ 1.3$ & $-/ 0.05$ & $-/ 2.4$ & $-1-$ & $-1-$ \\
\hline$\sigma_{p * S * i}^{2}$ & $-/ 0.00$ & $-/ 0$ & $-/ 0.00$ & $-/ 0$ & $-/ 0.01$ & $-/ 0.3$ & $-/-$ & $-1-$ \\
\hline
\end{tabular}




\begin{tabular}{|c|c|c|c|c|c|c|c|c|}
\hline$\sigma_{d * S * i}^{2}$ & $-/ 0.00$ & $-/ 0$ & $-/ 0.00$ & $-/ 0$ & $-/ 0.00$ & $-/ 0$ & $-1-$ & $-1-$ \\
\hline$\sigma_{\text {residual }}^{2}$ & $0.93 / 0.37$ & $62.6 / 25.8$ & $1.19 / 0.61$ & 64.4 / 31.6 & $1.08 / 0.59$ & $54.2 / 29.4$ & $1.76 / 1.76$ & 59.4 / 54.6 \\
\hline$\sigma_{\text {total }}^{2}$ & $1.48 / 1.44$ & $100 / 100$ & $1.85 / 1.94$ & $100 / 100$ & $1.99 / 2.01$ & $100 / 100$ & $2.95 / 3.22$ & $100 / 100$ \\
\hline$\alpha_{\text {ave }}$ & $-/ 0.82$ & & $-/ 0.77$ & & $-/ 0.84$ & & $-1-$ & \\
\hline$E_{\rho^{2}}$ & $0.87 / 0.84$ & & $0.83 / 0.77$ & & $0.92 / 0.89$ & & $0.76 / 0.85$ & \\
\hline$R_{c}$ & $-/ 0.77$ & & $-/ 0.69$ & & $-/ 0.75$ & & $-1-$ & \\
\hline mean & $5.04 / 4.81$ & & $4.10 / 4.12$ & & $2.67 / 2.96$ & & 4.34 / 4.71 & \\
\hline
\end{tabular}

Note: $\mathrm{EA}=$ energetic arousal; TA $=$ tense arousal; In interaction terms, $p=$ person, $d=$ day-of-week, $s=$ session, $i=i$ item. For ease of presentation, the results of Study 1 and Study 2 are separated by “"”. 
Table 2. Means, variance components, and reliability coefficients for items of state self-control capacity

\begin{tabular}{|c|c|c|c|c|c|c|c|c|}
\hline & SSC_con & $\%$ & SSC_wil & $\%$ & SSC_urg & $\%$ & SSC_mot & $\%$ \\
\hline$\sigma_{\text {person }}^{2}$ & $0.54 / 0.51$ & $20.1 / 16.1$ & $0.90 / 0.70$ & $37.5 / 27.2$ & $0.88 / 0.78$ & $39.0 / 31.2$ & $0.62 / 0.76$ & $26.4 / 32.1$ \\
\hline$\sigma_{\text {day-of-week }}^{2}$ & $0.01 / 0.00$ & $0.4 / 0.1$ & $0.01 / 0.00$ & $0.2 / 0$ & $0.01 / 0.01$ & $0.3 / 0.5$ & $0.01 / 0.00$ & $0.3 / 0.2$ \\
\hline$\sigma_{\text {session }}^{2}$ & $0.11 / 0.18$ & $4.1 / 5.6$ & $0.02 / 0.04$ & $0.9 / 1.5$ & $0.01 / 0.03$ & $0.6 / 1.0$ & $0.06 / 0.07$ & $2.4 / 3.0$ \\
\hline$\sigma_{p * d}^{2}$ & $0.19 / 0.21$ & $7.2 / 6.6$ & $0.15 / 0.18$ & $6.2 / 7.0$ & $0.14 / 0.21$ & $6.3 / 8.4$ & $0.19 / 0.16$ & $7.9 / 6.8$ \\
\hline$\sigma_{p * s}^{2}$ & $0.11 / 0.19$ & $4.3 / 5.9$ & $0.07 / 0.07$ & $2.9 / 2.6$ & $0.05 / 0.06$ & $2.2 / 2.3$ & $0.07 / 0.11$ & $3.1 / 4.5$ \\
\hline$\sigma_{d * s}^{2}$ & $0.01 / 0.02$ & $0.3 / 0.7$ & $0.00 / 0.01$ & $0.1 / 0.4$ & $0.00 / 0.00$ & $0 / 0.1$ & $0.01 / 0.00$ & $0.4 / 0.1$ \\
\hline$\sigma_{\text {residual }}^{2}$ & $1.70 / 2.08$ & $63.5 / 65.0$ & $1.25 / 1.57$ & $52.2 / 61.2$ & $1.16 / 1.42$ & $51.6 / 56.4$ & $1.41 / 1.26$ & $59.6 / 53.2$ \\
\hline$\sigma_{\text {total }}^{2}$ & $2.68 / 3.20$ & $100 / 100$ & $2.40 / 2.57$ & $100 / 100$ & $2.24 / 2.51$ & $100 / 100$ & $2.24 / 2.51$ & $100 / 100$ \\
\hline$E_{\rho^{2}}$ & $0.88 / 0.85$ & & $0.95 / 0.92$ & & $0.95 / 0.93$ & & $0.91 / 0.93$ & \\
\hline mean & $4.40 / 4.28$ & & $5.29 / 5.06$ & & $5.35 / 5.20$ & & $3.98 / 3.95$ & \\
\hline
\end{tabular}

Note: SSC con = state self-control, concentration; ssc_wil = state self-control, willpower; SSC urg = state self-control, urge control; SSC mot

$=$ state self-control, motivation; In interaction terms, $p=$ person, $d=$ day-of-week, $s=$ session, $i=i t e m$. For ease of presentation, the results of Study 1 and Study 2 are separated by “/”. 
Table 3. Means, variance components, and reliability coefficients for 4-item and 2-item state self-control scales

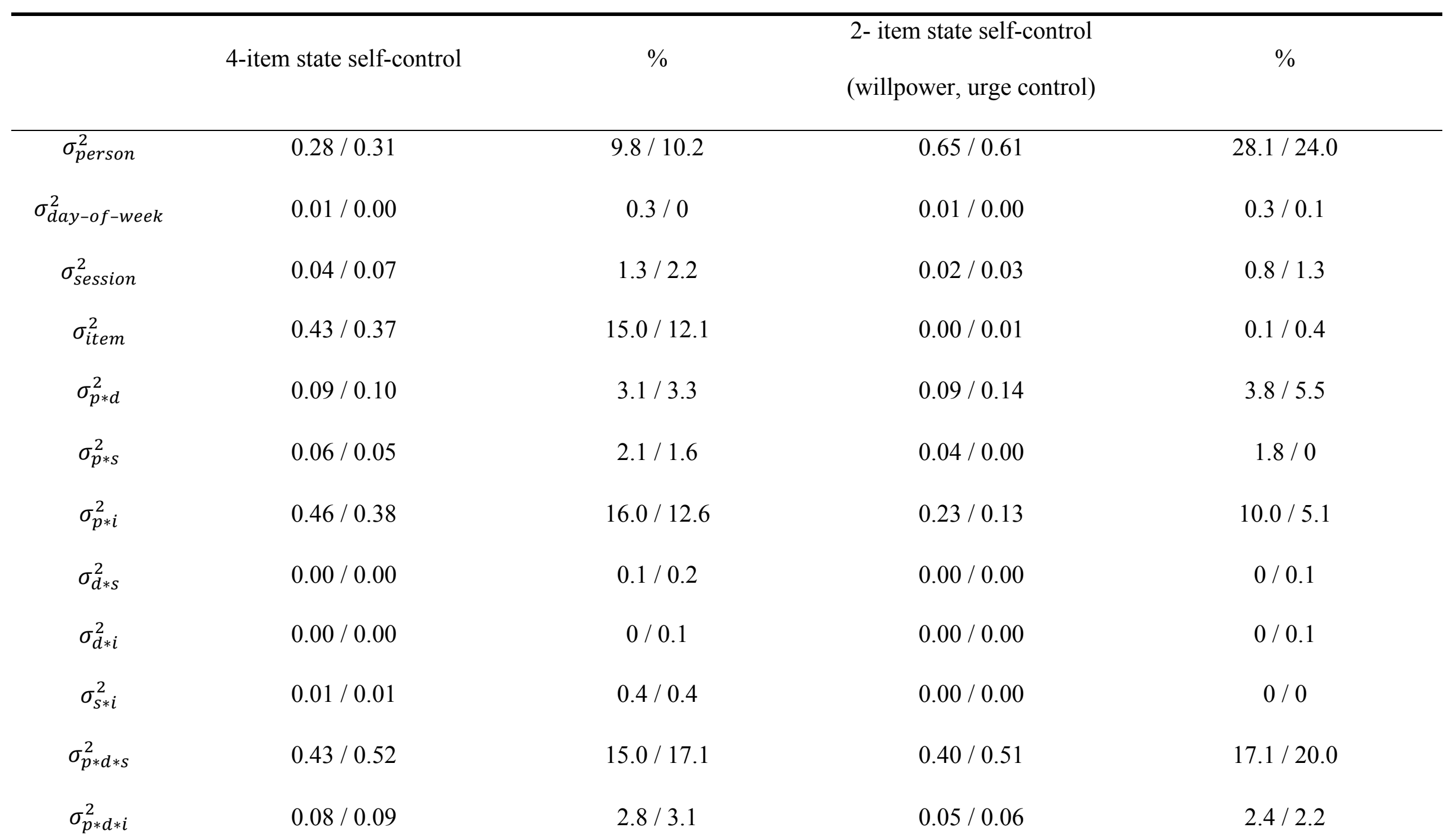




\begin{tabular}{|c|c|c|c|c|}
\hline$\sigma_{p * S * i}^{2}$ & $0.02 / 0.06$ & $0.6 / 1.9$ & $0.02 / 0.07$ & $0.7 / 2.8$ \\
\hline$\sigma_{d * S * i}^{2}$ & $0.00 / 0.01$ & $0.1 / 0.2$ & $0.00 / 0.00$ & $0 / 0.2$ \\
\hline$\sigma_{\text {residual }}^{2}$ & $0.95 / 1.06$ & $33.4 / 35.1$ & $0.81 / 0.98$ & $34.8 / 38.2$ \\
\hline$\sigma_{\text {total }}^{2}$ & $2.85 / 3.04$ & $100 / 100$ & $2.32 / 2.56$ & $100 / 100$ \\
\hline$E_{\rho^{2}}$ & $0.65 / 0.70$ & & $0.81 / 0.85$ & \\
\hline$R_{c}$ & $0.64 / 0.66$ & & $0.50 / 0.51$ & \\
\hline$\alpha_{\text {ave }}$ & $0.69 / 0.70$ & & $0.69 / 0.66$ & \\
\hline mean & $4.76 / 4.62$ & & $5.32 / 5.14$ & \\
\hline
\end{tabular}

Note: In interaction terms, $p=$ person, $d=$ day-of-week, $s=$ session, $i=i t e m$. For ease of presentation, the results of Study 1 and Study 2 are separated by “/”. 
Table 4. Results of the random-intercept and random-slope cosinor models

\begin{tabular}{|c|c|c|c|c|c|c|}
\hline \multirow{2}{*}{$\begin{array}{c}\text { State } \\
\text { Variable }\end{array}$} & \multicolumn{3}{|c|}{ Model 2} & \multicolumn{3}{|c|}{ Model 3} \\
\hline & $\begin{array}{l}\text { Model fit change } \\
\left(\Delta \text { pseudo- } R^{2}\right)\end{array}$ & Amplitude & Phase angles & $\begin{array}{l}\text { Model fit change } \\
\left(\Delta \text { pseudo- } R^{2}\right)\end{array}$ & Amplitude & Phase angles \\
\hline Valence & $1.5 \% / 1.3 \%$ & $0.18 / 0.16$ & $18: 52$ / 20:41 & $11.8 \% / 9.9 \%$ & $0.18 / 0.15$ & $18: 50 / 20: 34$ \\
\hline EA & $4.3 \% / 4.0 \%$ & $0.36 / 0.37$ & $15: 03 / 15: 05$ & $16.6 \% / 16.6 \%$ & $0.37 / 0.37$ & $15: 04 / 15: 11$ \\
\hline TA & $1.1 \% / 0.8 \%$ & $0.16 / 0.14$ & $13: 55 / 13: 06$ & $8.0 \% / 9.1 \%$ & $0.16 / 0.13$ & $13: 56 / 13: 14$ \\
\hline Sleepiness & $11.6 \% / 7.8 \%$ & $0.62 / 0.53$ & $3: 17 / 3: 03$ & $27.2 \% / 23.3 \%$ & $0.63 / 0.54$ & $3: 16 / 3: 06$ \\
\hline SSC_con & $5.2 \% / 5.7 \%$ & $0.37 / 0.36$ & $14: 14 / 13: 21$ & $14.4 \% / 19.1 \%$ & $0.36 / 0.37$ & $14: 09 / 13: 38$ \\
\hline SSC_wil & $1.3 \% / 1.5 \%$ & $0.17 / 0.16$ & $13: 11 / 11: 50$ & $7.9 \% / 9.1 \%$ & $0.17 / 0.17$ & $13: 01 / 12: 06$ \\
\hline SSC_urg & $0.7 \% / 1.1 \%$ & $0.11 / 0.14$ & $11: 05 / 11: 17$ & $7.3 \% / 7.4 \%$ & $0.10 / 0.13$ & $10: 50 / 11: 09$ \\
\hline SSC_mot & $3.1 \% / 3.7 \%$ & $0.28 / 0.27$ & $14: 26 / 13: 10$ & $11.9 \% / 11.5 \%$ & $0.27 / 0.27$ & $14: 25 / 13: 12$ \\
\hline
\end{tabular}

Note: For ease of presentation, the results of Study 1 and Study 2 are separated by “/”. 
Table 5. Between-person correlation matrix of state measures

\begin{tabular}{|c|c|c|c|c|c|c|c|c|}
\hline & Valence & EA & TA & Sleepiness & SSC_con & SSC_wil & SSC_urg & $\overline{\text { SSC_mot }}$ \\
\hline Valence & 1 & & & & & & & \\
\hline EA & $0.64 / 0.68$ & 1 & & & & & & \\
\hline TA & $-0.56 /-0.46$ & $-0.33 /-0.28$ & 1 & & & & & \\
\hline Sleepiness & $-0.51 /-0.43$ & $-0.66 /-0.52$ & $0.33 / 0.27$ & 1 & & & & \\
\hline SSC_con & $0.31 / 0.32$ & $0.27 / 0.36$ & $-0.46 /-0.36$ & $-0.43 /-0.48$ & 1 & & & \\
\hline SSC_wil & $0.50 / 0.24$ & $0.34 / 0.25$ & $-0.55 /-0.35$ & $-0.38 /-0.23$ & $0.65 / 0.60$ & 1 & & \\
\hline SSC_urg & $0.32 / 0.17$ & $0.16 / 0.12$ & $-0.47 /-0.47$ & $-0.30 /-0.19$ & $0.58 / 0.55$ & $0.71 / 0.76$ & 1 & \\
\hline $\mathrm{SSC}$ mot & $0.13 / 0.23$ & $0.35 / 0.30$ & $-0.04 / 0.02$ & $-0.36 /-0.17$ & $0.14 / 0.24$ & $0.08 / 0.24$ & $-0.04 / 0.09$ & 1 \\
\hline
\end{tabular}

Note: For ease of presentation, the results of Study 1 and Study 2 are separated by “"”. 
Table 6. Within-person correlation matrix of state measures

\begin{tabular}{|c|c|c|c|c|c|c|c|c|}
\hline & Valence & EA & $\mathrm{TA}$ & Sleepiness & SSC_con & SSC_wil & SSC_urg & SSC_mot \\
\hline Valence & 1 & & & & & & & \\
\hline EA & $0.43 / 0.44$ & 1 & & & & & & \\
\hline TA & $-0.28 /-0.36$ & $-0.06 /-0.03$ & 1 & & & & & \\
\hline Sleepiness & $-0.34 /-0.28$ & $-0.56 /-0.54$ & $0.01 /-0.02$ & 1 & & & & \\
\hline SSC_con & $0.23 / 0.19$ & $0.37 / 0.36$ & $-0.05 /-0.01$ & $-0.41 /-0.38$ & 1 & & & \\
\hline SSC_wil & $0.36 / 0.31$ & $0.32 / 0.39$ & $-0.16 /-0.15$ & $-0.33 /-0.33$ & $0.41 / 0.45$ & 1 & & \\
\hline SSC_urg & $0.16 / 0.14$ & $0.14 / 0.18$ & $-0.08 /-0.11$ & $-0.18 /-0.19$ & $0.30 / 0.30$ & $0.35 / 0.34$ & 1 & \\
\hline SSC mot & $0.27 / 0.23$ & $0.36 / 0.33$ & $-0.02 /-0.04$ & $-0.35 /-0.28$ & $0.33 / 0.34$ & $0.33 / 0.32$ & $0.25 / 0.23$ & 1 \\
\hline
\end{tabular}

Note: For ease of presentation, the results of Study 1 and Study 2 are separated by “/”. 
Figure 1. Effects of trait self-control on the diurnal pattern of valence and stress in Study 1
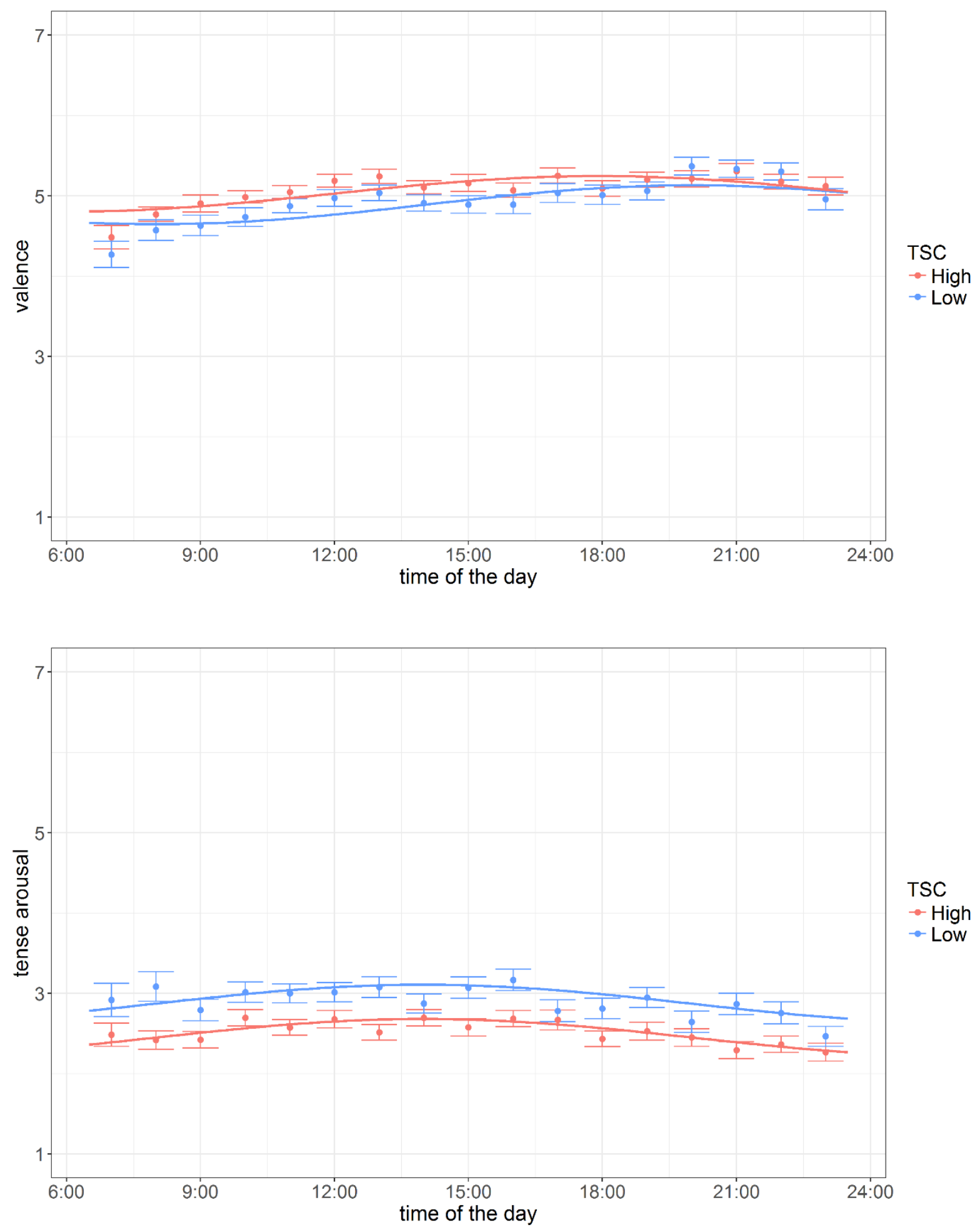

Note: Effects of trait self-control (TSC) on the diurnal patterns of valence (top) and tense arousal (bottom) in Study 1. Mean values with error bars (one SE) are shown for different hours of the day. 
Figure 2. Forest plot of the correlation between trait self-control and affective valence

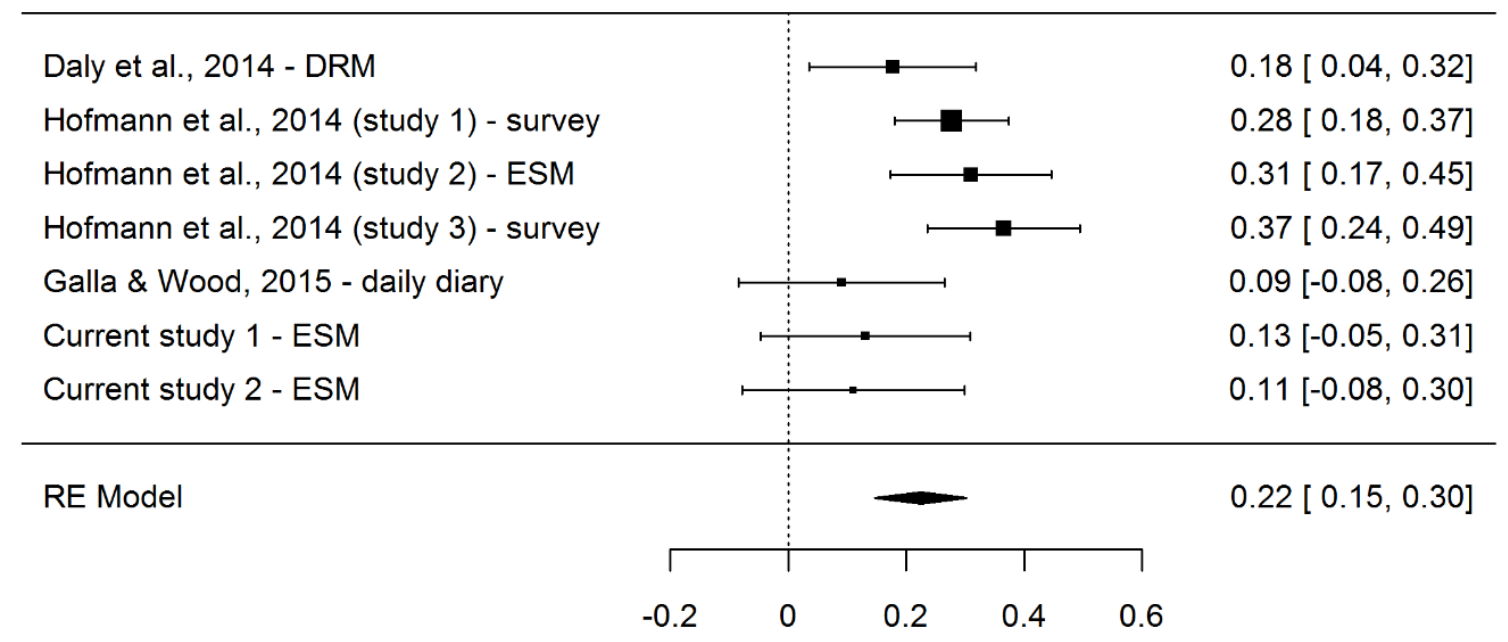

Fisher's z Transformed Correlation Coefficient

Note: Forest plot of the correlation between trait self-control and affective valence. The metaanalytic effect size and 95\% CIs were estimated using a random-effect model. (DRM = day reconstruction method; ESM = experience sampling method) 
Figure 3. Forest plot of the correlation between trait self-control and stress (tense arousal)

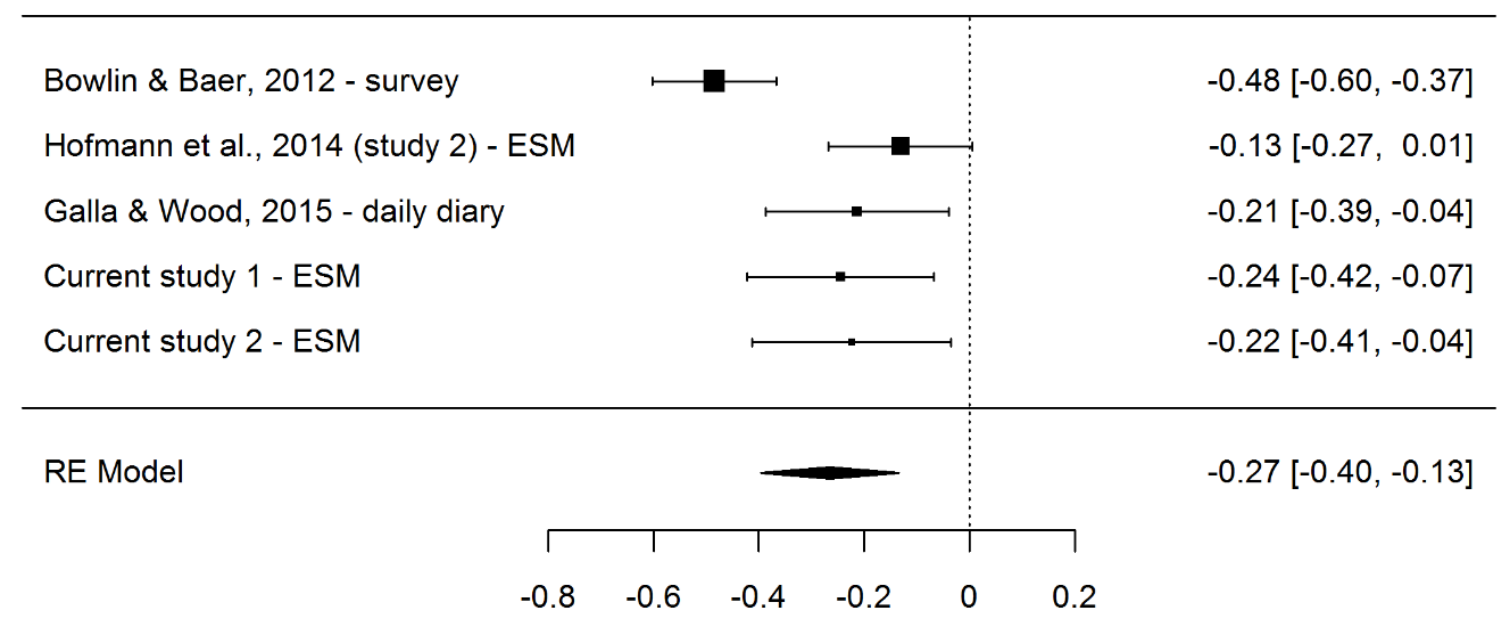

Fisher's z Transformed Correlation Coefficient

Note: Forest plot of the correlation between trait self-control and stress (tense arousal). The meta-analytic effect size and 95\% CIs were estimated using a random-effect model. (ESM = experience sampling method) 